Supporting Information

\title{
Catalytic Synergy on PtNi Bimetal Catalysts Driven by Interfacial Intermediate Structure
}

Taek-Seung Kim, ${ }^{+, \ddagger}$ Jeongjin Kim, ${ }^{\ddagger}$ Hee Chan Song, ${ }^{\dagger \neq}{ }^{\ddagger}$ Daeho Kim, ${ }^{\dagger, \neq}$ Beomgyun Jeong, ${ }^{\S}$ Jouhahn Lee, ${ }^{\S}$ Jae Won Shin, ${ }^{\ddagger}$ Ryong Ryoo, ${ }^{\dagger, \neq}$ and Jeong Young Park ${ }^{*+, \neq}$

${ }^{\dagger}$ Department of Chemistry, Korea Advanced Institute of Science and Technology (KAIST), Daejeon 34141, Republic of Korea.

${ }^{\ddagger}$ Center for Nanomaterials and Chemical Reactions, Institute for Basic Science (IBS), Daejeon 34141, Republic of Korea.

${ }^{\S}$ Research Center for Materials Analysis, Korea Basic Science Institute (KBSI), Daejeon 34133, Republic of Korea.

*To whom correspondence should be addressed. E-mail: jeongypark@kaist.ac.kr

\section{Contents}

Figure S1 - S15

Caption for Movie S1

Other Supporting information for this manuscript include the following:

Movie S1 


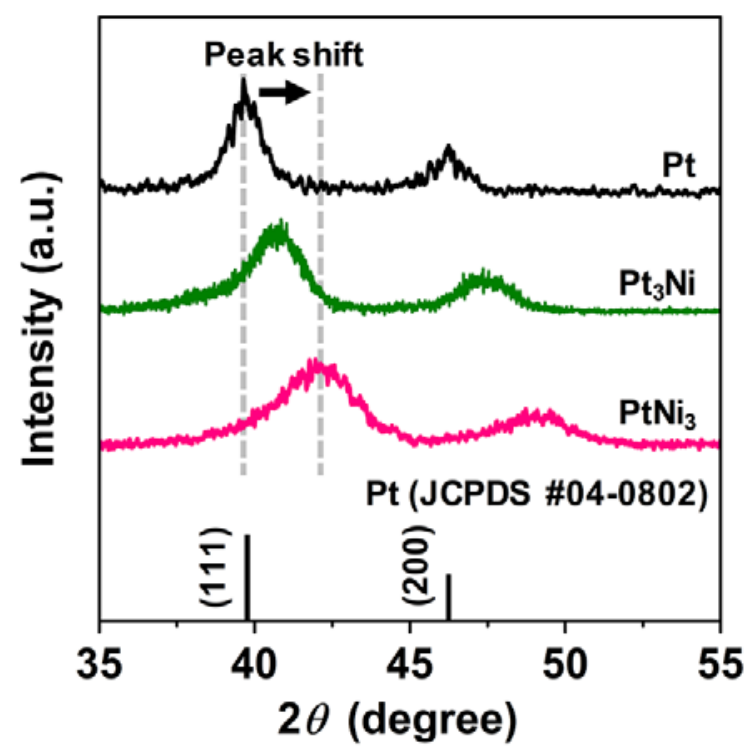

Figure S1. Microstructure analysis of as-synthesized samples. XRD patterns of $\mathrm{Pt}_{1} \mathrm{Pt}_{3} \mathrm{Ni}$, and PtNi3 nanoparticles with reference Pt (JCPDS \#04-0802). 

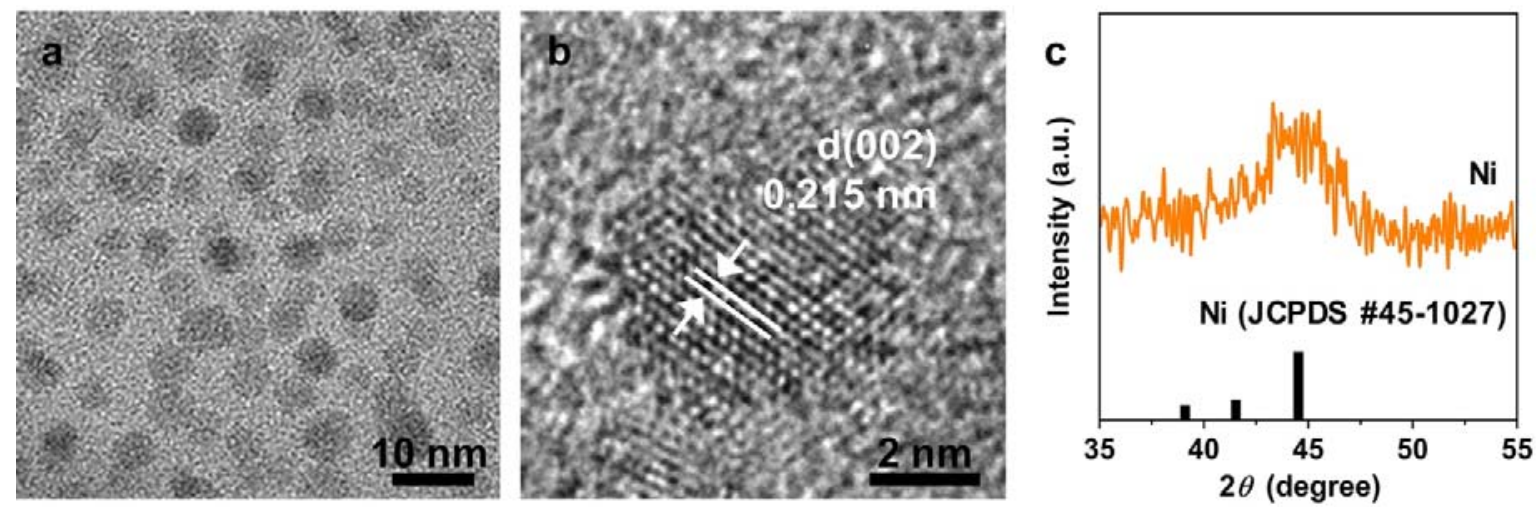

Figure S2. Characterization of as-synthesized Ni nanoparticles. Representative (a) TEM, (b) HRTEM images, and (c) XRD pattern of as-synthesized Ni nanoparticles with reference Ni (JCPDS \#45-1027). 


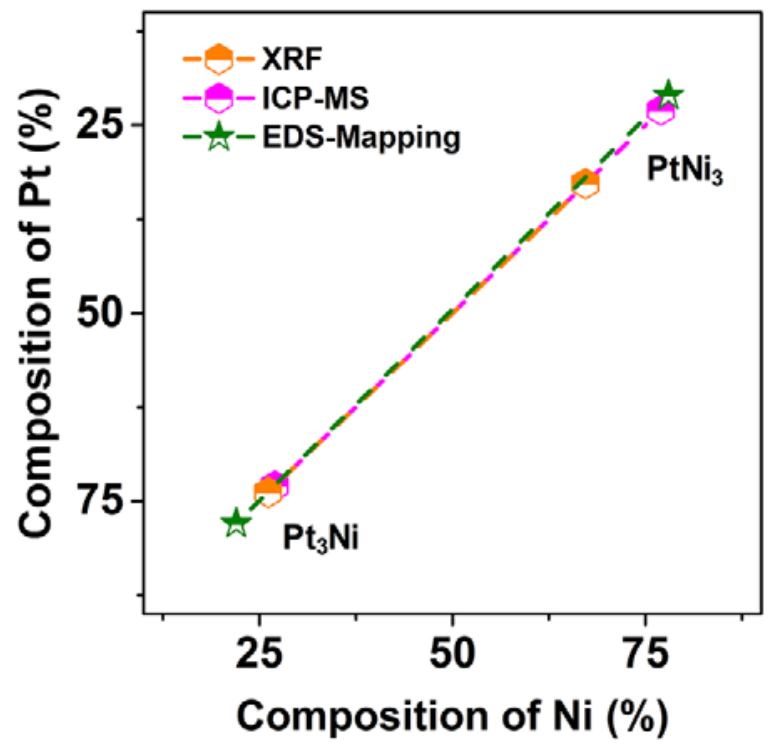

Figure S3. Chemical composition analysis of as-synthesized samples. Composition plot of assynthesized $\mathrm{Pt}_{3} \mathrm{Ni}$ and $\mathrm{PtNi} 3$ nanoparticles with atomic ratios of $\mathrm{Pt}$ to Ni by XRF, ICP-MS, and EDS-Mapping analysis. 

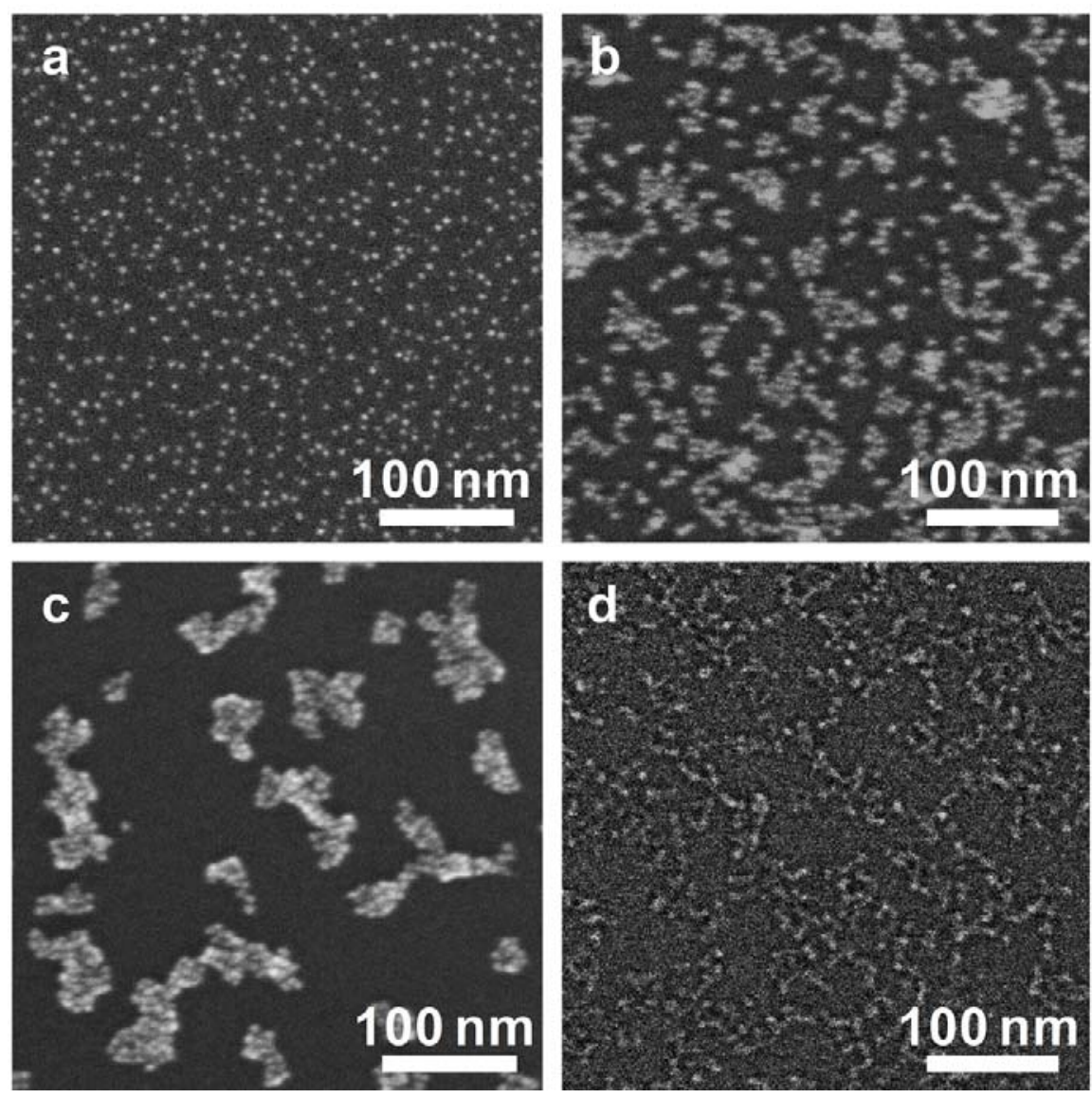

Figure S4. Sample preparation for batch reactor by Langmuir Blodgett technique. Scanning electron microscopy (SEM) images of (a) Pt, (b) Pt 3 Ni, (c) PtNi3, and (d) Ni nanoparticles on a $\mathrm{SiO}_{2}$ substrate. 


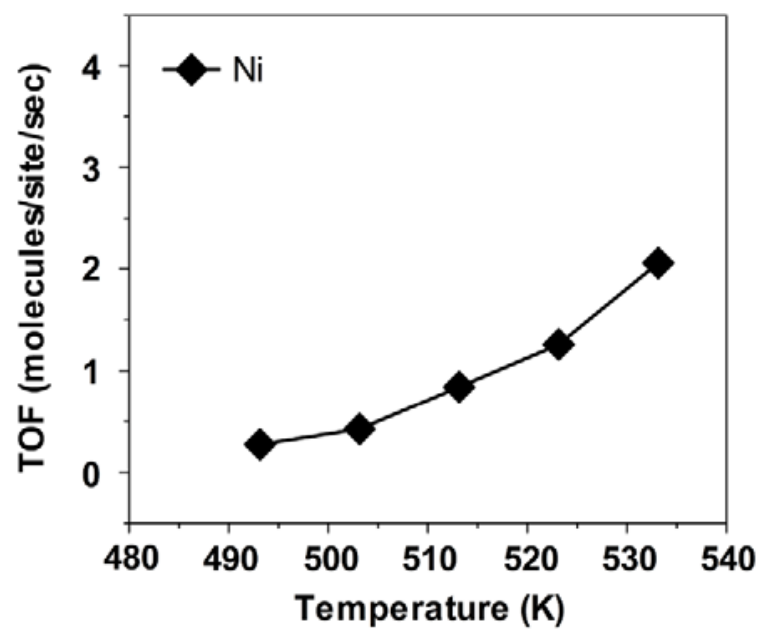

Figure S5. Reaction data for CO oxidation of as-synthesized Ni nanoparticles. Catalytic activity for $\mathrm{CO}$ oxidation of $\mathrm{Ni}$ catalyst on the $\mathrm{SiO}_{2}$ substrate obtained by batch reactor under 40 Torr $\mathrm{CO}$, 100 Torr $\mathrm{O}_{2}$ and 620 Torr $\mathrm{He}$ mixed gas (reactant gas: $\mathrm{CO}+\mathrm{O}_{2} ; 1: 2.5$ ratio, balancing gas: $\mathrm{He}$ ). 


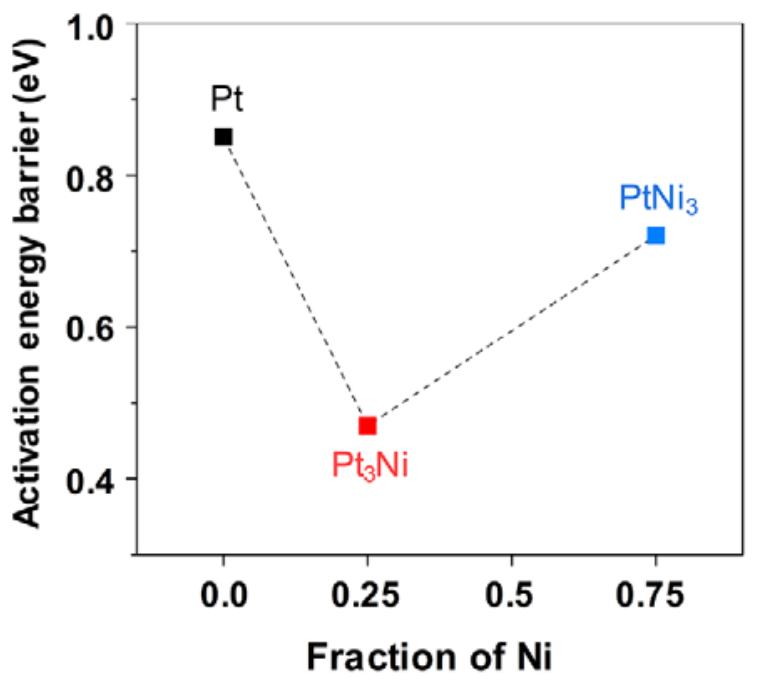

Figure S6. Activation energy barriers for $\mathrm{CO}$ oxidation. Activation energy barriers for $\mathrm{CO}$ oxidation reaction of $\mathrm{Pt}, \mathrm{Pt}_{3} \mathrm{Ni}$, and $\mathrm{PtNi}_{3} \mathrm{Pt}$ catalysts on the $\mathrm{SiO}_{2}$ support obtained by flow reaction in DRIFT reaction cell. Measurement was operated under $100 \mathrm{ml} \mathrm{min}^{-1}$ of $\mathrm{CO} / \mathrm{O}_{2} / \mathrm{He}$ gas mixture flow $\left(\mathrm{CO}+\mathrm{O}_{2}\right.$ feed, 1:2.5 ratio) at the elevated temperature. 

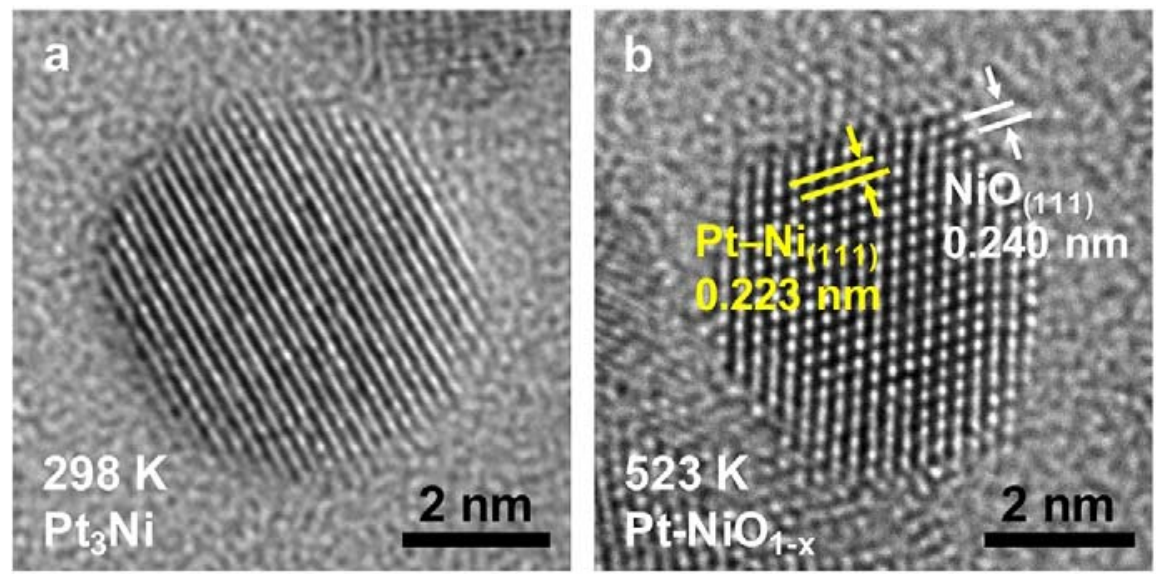

Figure S7. Formation of $\mathrm{Pt}-\mathrm{NiO}_{1-\mathrm{x}}$ interfacial nanostructure on $\mathrm{Pt}_{3} \mathrm{Ni}$ nanoparticle surface by $e x$ situ HRTEM analysis. Representative HRTEM images of $\mathrm{Pt}_{3} \mathrm{Ni}$ nanoparticle (a) before and (b) after annealing process at $523 \mathrm{~K}$ in $\mathrm{O}_{2}$ condition. 

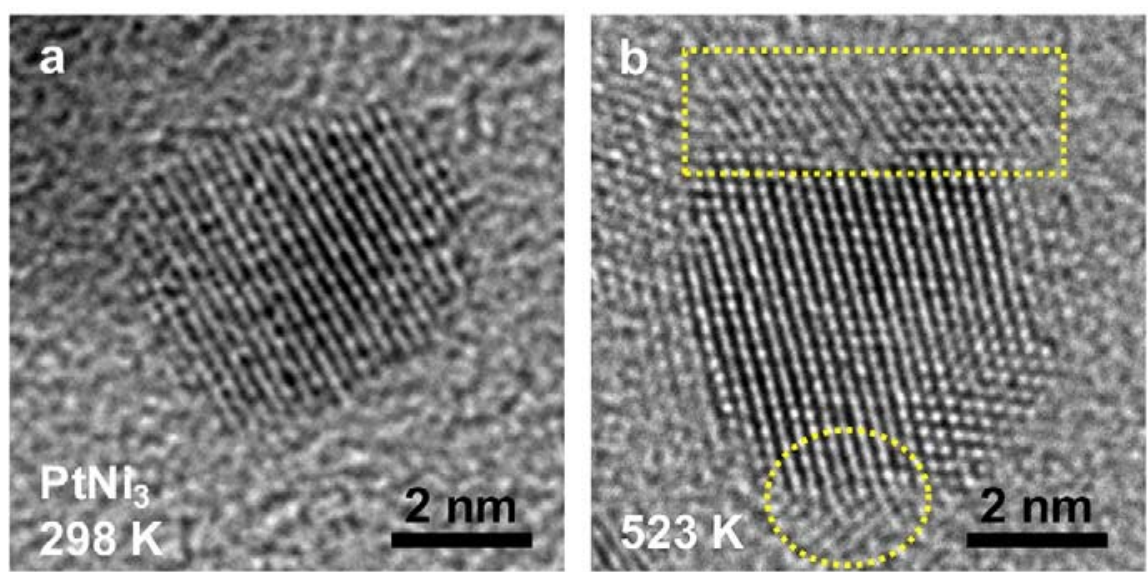

Figure S8. Formation of $\mathrm{NiO}$ island on PtNiz nanoparticle surface by ex situ HRTEM analysis. Representative HRTEM images of PtNiz nanoparticle (a) before and (b) after the annealing process at $523 \mathrm{~K}$ in $\mathrm{O}_{2}$ condition. 


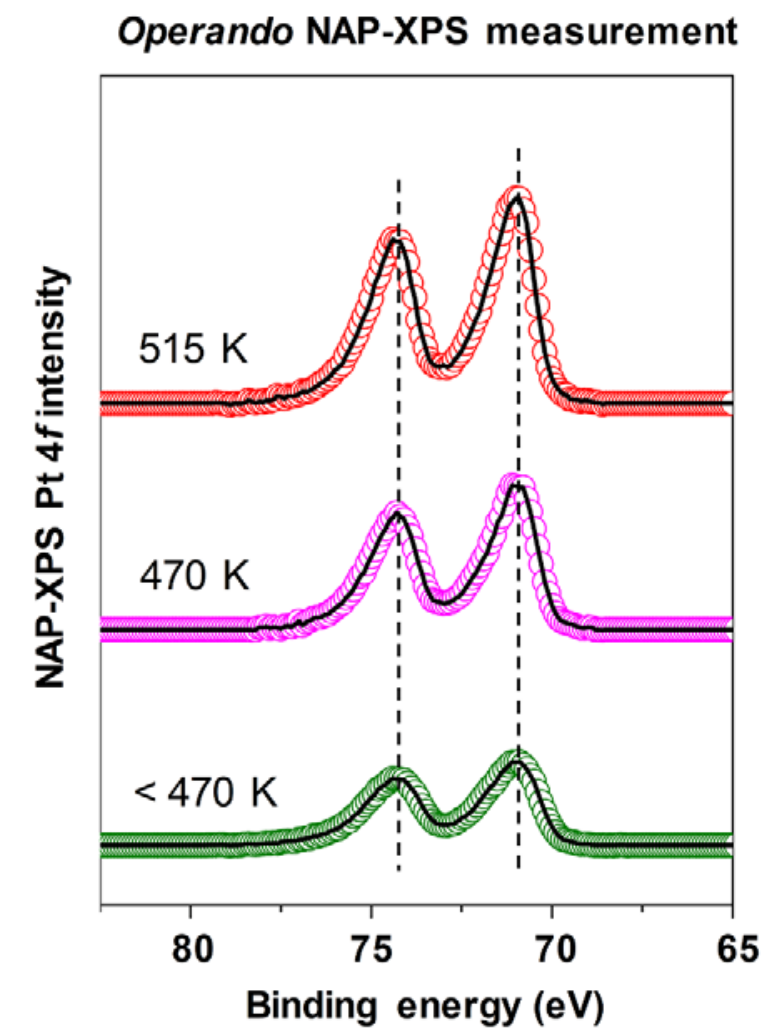

Figure S9. Operando NAP-XPS measurement of Pt 3 Ni nanoparticles. Pt $4 f$ core-level XP spectra at elevated temperatures $(<470,470,515 \mathrm{~K})$ under 300 mTorr $\mathrm{CO}$ and 750 mTorr $\mathrm{O}_{2}$ mixed gas (1:2.5 ratio) at elevated temperatures. The spectra were processed by subtracting the Shirley background. 


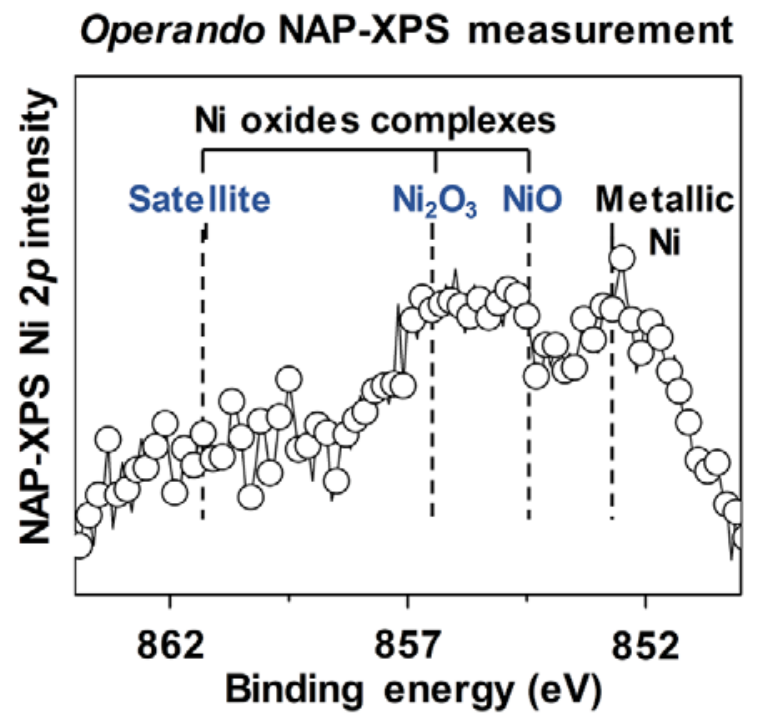

Figure S10. Operando NAP-XPS measurement of $\mathrm{Pt}_{3} \mathrm{Ni}$ NPs after $\mathrm{CO}$ oxidation reaction in UHV. The Ni $2 p$ core-level XP spectrum after evacuation of mixed gas $\left(\mathrm{CO}: \mathrm{O}_{2}=1: 2.5\right)$ at $298 \mathrm{~K}$. The spectrum was processed by subtracting the Shirley background. 

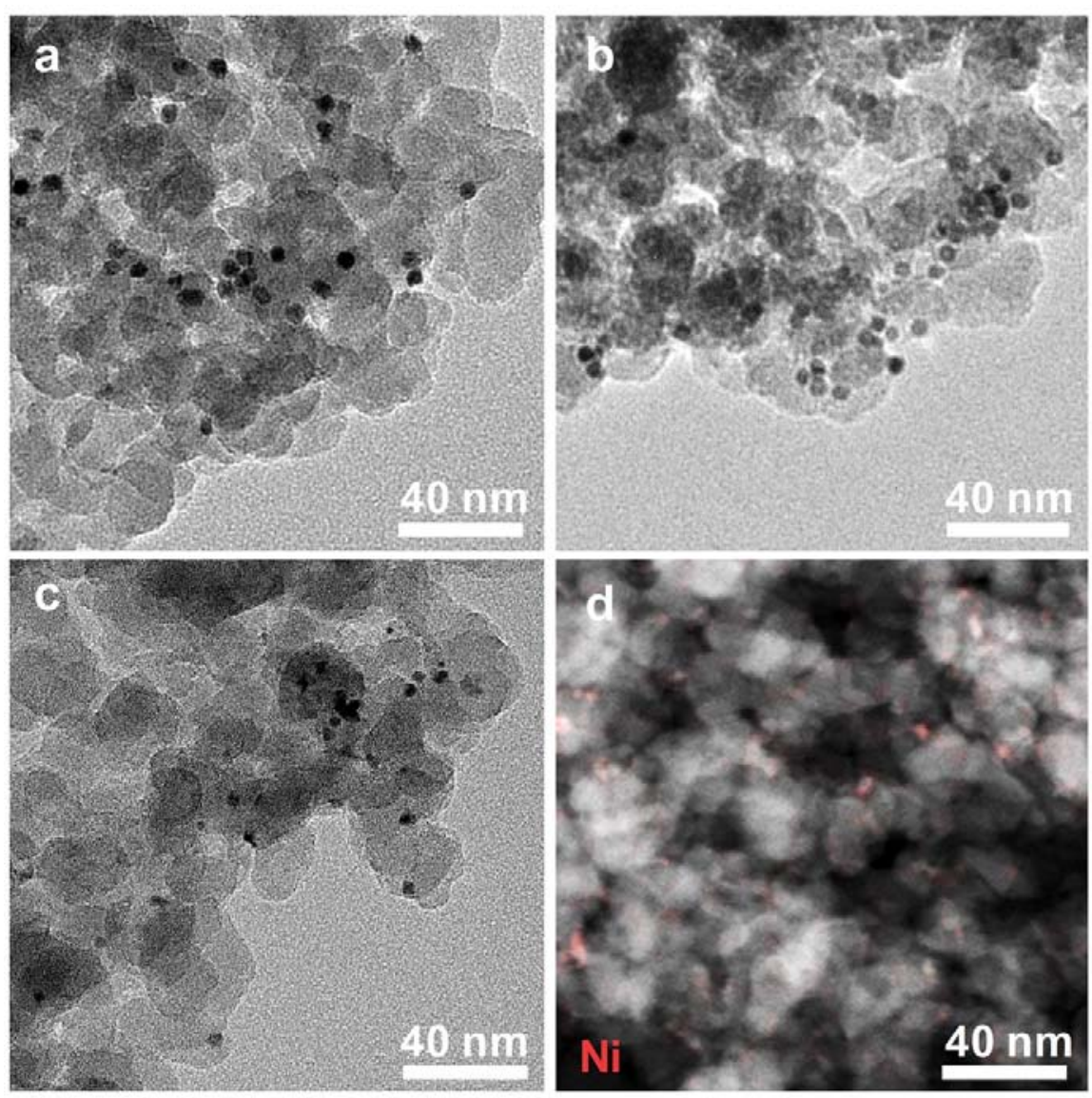

Figure S11. Sample preparation for operando DRIFT measurement. Representative TEM images of (a) $\mathrm{Pt}$, (b) $\mathrm{Pt}_{3} \mathrm{Ni}$, and (c) $\mathrm{PtNi}_{3}$ nanoparticles on the $\mathrm{SiO}_{2}$ support. (d) Representative STEM image with Ni elemental mapping of Ni nanoparticles on the $\mathrm{SiO}_{2}$ support. 

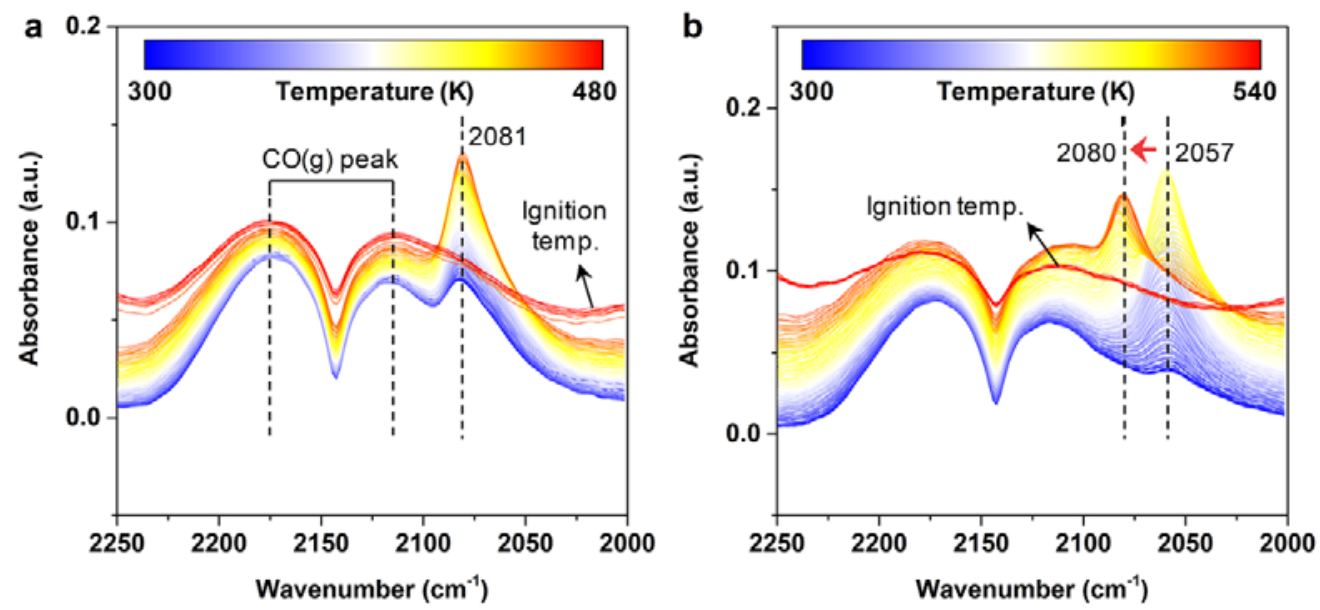

Figure S12. DRIFT measurement during CO oxidation at elevated temperatures. IR Spectra for $\mathrm{CO}$ adsorption as a function of $\mathrm{CO}$ oxidation temperature for samples (a) $\mathrm{Pt}_{3} \mathrm{Ni}$ and (b) $\mathrm{Pt}$ catalysts. 

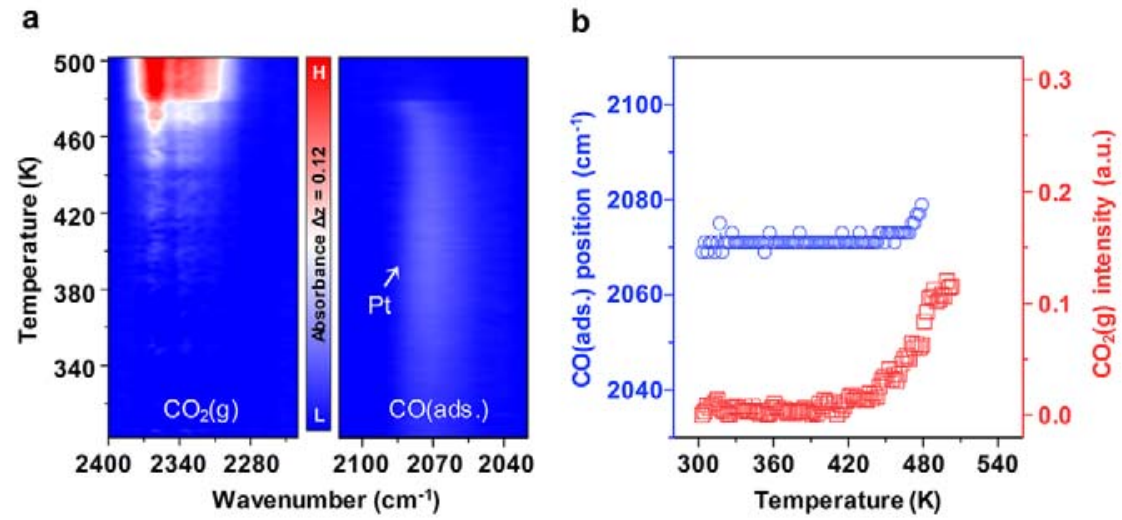

Figure S13. DRIFT measurement during CO oxidation at elevated temperatures. (a) Contourmaps of the operando DRIFT spectra during the reaction of $\mathrm{PtNi}_{3}$ catalyst on the $\mathrm{SiO}_{2}$ support. (b) Plots of linear $v(\mathrm{C} \equiv \mathrm{O})$ peak position with the intensity of $v$ as $(\mathrm{C}=\mathrm{O})$ band for $\mathrm{PtNi}$ iz catalyst. DRIFT measurement was operated under $100 \mathrm{ml} \mathrm{min}^{-1}$ of $\mathrm{CO} / \mathrm{O}_{2} / \mathrm{He}$ gas mixture flow $\left(\mathrm{CO}+\mathrm{O}_{2}\right.$ feed, 1:2.5 ratio) at the elevated temperature. 


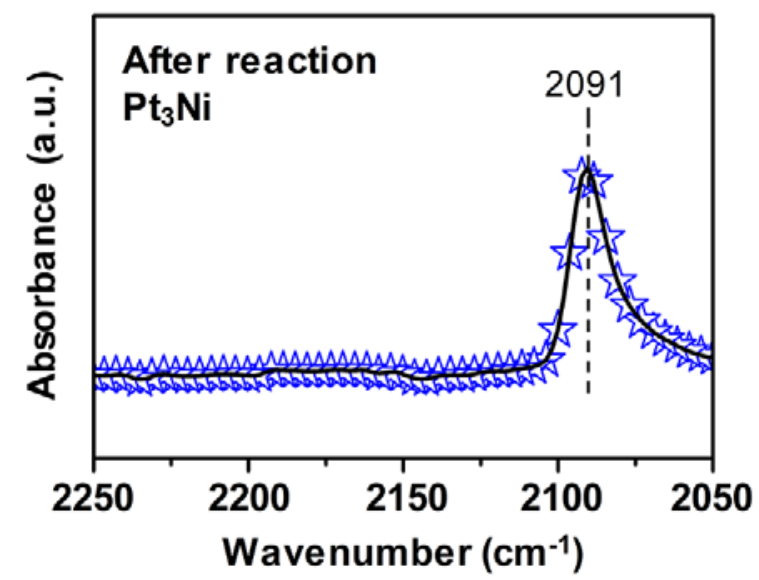

Figure S14. DRIFT spectrum of $\mathrm{Pt}_{3} \mathrm{Ni}$ catalyst after $\mathrm{CO}$ oxidation reaction. IR spectrum for $\mathrm{CO}$ adsorption on $\mathrm{Pt}_{3} \mathrm{Ni}$ catalyst after $\mathrm{CO}$ oxidation reaction at $298 \mathrm{~K}$. 


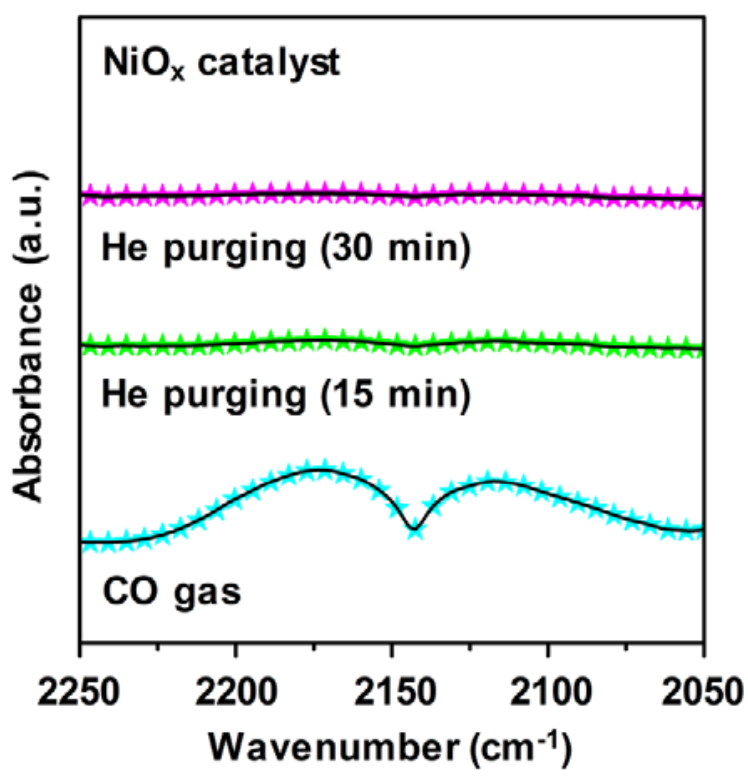

Figure S15. DRIFT spectra of $\mathrm{NiO}_{x}$ catalyst. IR spectra of $\mathrm{NiO}_{x}$ catalyst on $\mathrm{SiO}_{2}$ support for $\mathrm{CO}$ adsorption under $\mathrm{CO}$ gas condition and He purging after 15 and $30 \mathrm{~min}$. 


\section{Caption for Movie S1}

\section{Movie S1}

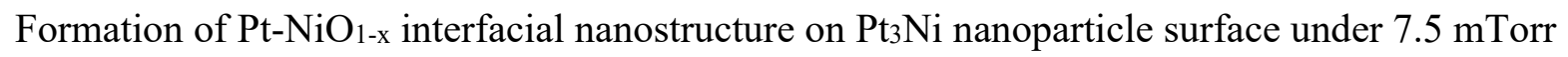
of $\mathrm{O}_{2}$ gas at $395 \mathrm{~K}$. 